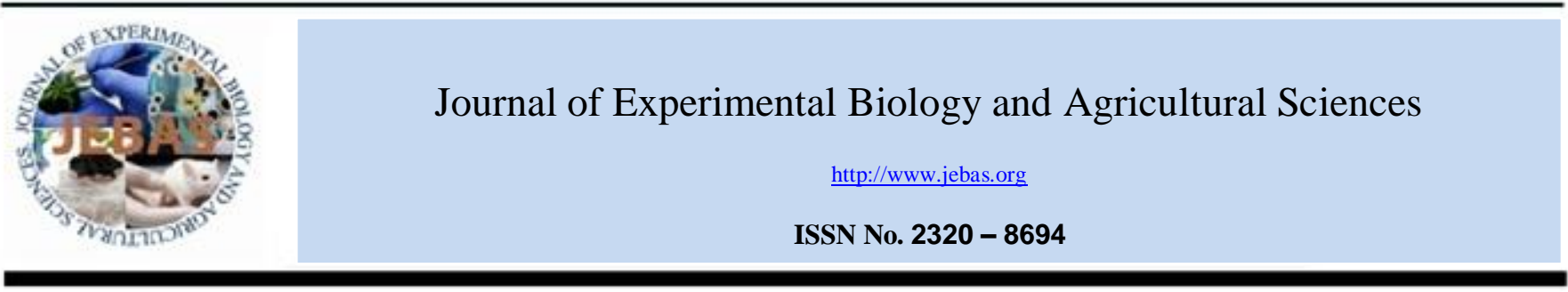

\title{
IDENTIFICATION AND PURIFICATION OF NOVEL CHLOROGENIC ACIDS IN Artemisia annua L.
}

\section{Wenwen Zhao ${ }^{1}$, Weina Zhang ${ }^{1}$, Yuru Chen ${ }^{1, *}$, Fengping Yang $^{1}$, Qiming $\mathrm{Cao}^{2}$, Wenzhong $\mathrm{Chen}^{3}$, Junli $\mathrm{Liu}^{4}$ and Kewei Dai ${ }^{5}$}

${ }^{1}$ College of Life Science, Nanjing Normal University, Nanjing Engineering Research Center for Industrialization of Microbial Resources, Jiangsu Key Lab for Biodiversity and Biotechnology, Jiangsu Key Lab for Microbes and Functional Genomics. Nanjing 210023, P. R. China

${ }^{2}$ School of Resources and Environment, University of Electronic Science and Technology of China, Chengdu 610054, P.R. China

${ }^{3}$ Nanjing Luye Sike Pharmaceutical Co., Ltd. Nanjing, 210061, P. R. China

${ }^{4}$ Institute of Chemical Industry of Forest Products, CAF, Nanjing 210042, P. R. China

${ }^{5}$ College of Geography Science, Nanjing Normal University, Nanjing 210023, P. R. China

Received - August 28, 2015; Revision - September 14, 2015; Accepted - October 04, 2015

Available Online - October 20, 2015

DOI: http://dx.doi.org/10.18006/2015.3(5).415.422

KEYWORDS
Artemisia annua L.
Chlorogenic acids
Dicaffeoylquinic acids
LC/MS
Identification
Purification

* Corresponding author

E-mail: chenyuru@njnu.edu.cn (Yuru Chen)

Peer review under responsibility of Journal of Experimental Biology and Agricultural Sciences.

Production and Hosting by Horizon Publisher (www.myvision.webs.com/horizon.html).

All rights reserved.

\begin{abstract}
Present work has been carried out to study the identification and purification of chlorogenic acids in Artemisia аппиа L. Thirty-six chlorogenic acids were identified from this plant. Among these fifteen viz. two monocaffeoylquinic acids (Mr354), five dicaffeoylquinic acids (Mr516), one feruloylquinic acid (Mr368), three caffeoylferuloylquinic acids (Mr530), two ferulylquinic acids (Mr544), one dimethoxy-cinnamoylquinic acid (Mr382) and one p-coumaroylquinic acid $(\mathrm{Mr} 338)$ were reported first time in present study by $\mathrm{LC} / \mathrm{MS}^{\mathrm{n}}$. Cis-isomers of these chlorogenic acids were also identified. Furthermore, column chromatography was used for the separation and purification of these chlorogenic acid; by the use of petroleum ether and ethyl acetate decolorization methods as mentioned in the literature, thus separation and purification process carried out at the same time. Polyamide and dextran were also used to purify Dicaffeoylquinic acid and purity level reached $85.7 \%$ with a yield of $53.4 \%$ after the secondary purification by Sephadex LH-20. Result of study revealed that A. annua can not only used for the production of artemisinin, but also yielding different kinds of chlorogenic acids, thus making comprehensive utilization of this plant.
\end{abstract}

All the article published by (Journal of Experimental Biology and Agricultural Sciences) / CC BY-NC 4.0

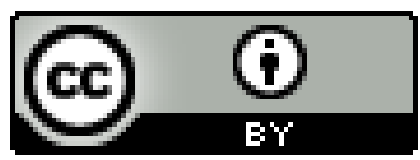




\section{Introduction}

Recently, much attention has been paid by world research community for the exploitation of medicinal plants. Artemisia аппиа $L$. is a functional plant used as a natural resource of Chinese herbal medicine in the production of artemisinin. This plant is widely used for the treatment of malaria and fever from many centuries due to its important antimalarial ingredient artemisinin (Clifford, 2000). It is believed that medicinal effects of artemisinin can be enhanced to treat parasitic diseases and cancer if it simultaneously delivered with flavonoids analogs extracted from A. annua (Clifford et al., 2006). Furthermore, remarkable anti-HIV activity of $A$. annua plant was also reported by various researchers (Mueller et al., 2000; Clifford et al., 2003). In addition, A. апnиa leaves contain variety of chlorogenic acids (Willcox et al., 2011), known as potential and nontoxic HIV-1 Integrase Inhibitors (Ferreira et al., 2010; Lubbe et al., 2011). Therefore, chlorogenic acids may be potential candidates in anti-HIV treatment.

Chlorogenic acids belongs to a large family of esters condensed by quinic acid (such as shikimic acid, queenie methyl or butyl 4-deoxy-quinic acid ) and trans-cinnamic acids (such caffeic, ferulic, p-coumaric, sinapic and dimethoxycinnamic acid)( Robinson et al., 1996; Lai et al., 2007; Gu et al., 2007). In IUPAC system (-)-quinic acid is defined as $1 \mathrm{~L}-1(\mathrm{OH})$, 3,4/5-tetrahydroxy-cyclohexane carboxylic acid and this same nomenclature is used throughout this paper (Han et al., 2008).

Crude acetone, water and methanol can be used to determined phenolic compositions of A. аппиа by HPLC-DAD-ESI/MS ${ }^{\mathrm{n}}$ (IUPAC, 1976; Carbonara et al., 2012; .Gouveia \& Castilho, 2013) but these compounds have not been fully studied so far. For this reason, it is necessary to develop a rapid and sensitive method to identify these components in A. апnиа. Therefore, present study has been conducted to develop a rapid and sensitive method for isolation and identification of chlorogenic acids from A. annua.

\section{Materials and Methods}

\subsection{Chemicals and reagents}

HPLC-grade acetonitrile was purchased from Merck (Darmstadt, Germany). All aqueous solutions were prepared with pure water produced by Milli-Q system (Bedford, MA, USA). Other organic solvents and chemical reagents were analytical grade were purchased from Tingbest Co. (Nanjing, China). 5-caffeoylquinic acid, caffeic acid and 4,5dicaffeoylquinic acid ( $>98 \%$ by HPLC for all) were obtained from Chengdo Biopurify Phytochemicals, Ltd China (Sichuan, China). Polyamide and dextran were purchased from Al Essex Bio-Technology Co., Ltd. Chengdu. A. апnиa and its residue (Chongqing, P. R. China) were smashed into 40 mesh by a pulverizer and then stored at room temperature.

\subsection{Sample preparation}

Extract of A. апnиa was obtained by dissolving $1 \mathrm{~g}$ of standard sample into $100 \mathrm{~mL}$ ethanol: water $(70: 30, \mathrm{v} / \mathrm{v})$ under ultrasonication for $1 \mathrm{~h}$ at $50^{\circ} \mathrm{C}$. After extraction, the sample was centrifuged at $6000 \mathrm{~g}$ for $3 \mathrm{~min}$, and stored at $-4{ }^{\circ} \mathrm{C}$ for analysis. Before HPLC analysis, the sample was filtered through $0.45 \mu \mathrm{m}$ filter.

\subsection{Analytical method}

Ethanolic extracts of A. аппиа are used for isolating phenolic compounds while $0.05 \%$ (v/v) acetic acid was used as additives to adjust the $\mathrm{pH}$ value of the mobile phase.

\subsubsection{Liquid chromatography}

The chromatography was performed on Ultimate AQ-C18 ( $250 \mathrm{~mm} \times 4.6 \mathrm{~mm}, 5 \mu \mathrm{m})$. The mobile phase consisted of $0.05 \%$ $(\mathrm{v} / \mathrm{v})$ acetic acid in water (A) and acetonitrile (B). The gradient program was used as follows with a total analysis time of 45 min: $(88 \%$ A $-60 \%$ A. The column temperature was maintained at $30^{\circ} \mathrm{C}$. The flow rate was $0.6 \mathrm{~mL} / \mathrm{min}$ and the injection volume was $10 \mu \mathrm{L}$. UV-DAD detection was performed at $\lambda=327 \mathrm{~nm}$.

\subsubsection{Mass spectrometry}

HPLC system interfaced with an Agilent 6460 triple quadrupole mass spectrometer (Agilent technologies, MA, USA) was used to carry out the HPLC/ DAD/ESI-MS/MS analysis, with the same column, elution program and flow rate of HPLC analysis. The conditions of ESI source were set as follows: source voltage: $3.5 \mathrm{kV}$; the flow rate of drying gas $\left(\mathrm{N}_{2}\right)$ was $11.0 \mathrm{~L} / \mathrm{min}$; the drying gas temperature was $365^{\circ} \mathrm{C}$ and nebulizer pressure of $45 \mathrm{psi}$. The mass spectrometric data was acquired from m/z 50 to 800 in negative ion modes. As necessary, $\mathrm{MS}^{2}$ fragment-targeted experiments were performed to focus only on compounds producing a parent ion at $\mathrm{m} / \mathrm{z} 353$, $515,367,529,543$ or 677 . The first level of impact energy was $5 \mathrm{ev}$; the second level of impact energy was $5 \mathrm{ev}, 10 \mathrm{ev}, 15 \mathrm{ev}$, $20 \mathrm{ev}$.

\subsection{Separation and purification of dicaffeoylquinic acid}

Polyamide (for initial purification) and dextran (for secondary purification) were used to purify dicaffeoylquinic acid and then eluted with different concentrations of ethanol. Finally, the content of dicaffeoylquinic acid was determined by HPLC to calculate the purity and yield.

\section{Results and Discussion}

Total thirty six chlorogenic acids were isolated from the leaves of A. аппиа. HPLC results of all isolated chlorogenic acids from A. аппиа leaves and A. аппиа residue were represented in Figure 2 and Figure 3. The identification of each compound 
were separated and out of which fifteen were reported for the first time on the total ion chromatogram (TIC). The TIC of representative A. аппиа extracts was shown in Figure 1.

Table 1 Varities of chlorogenic acids detected in A. аппиа

\begin{tabular}{|c|c|c|c|c|}
\hline No. & Rt (min) & $\left(\mathbf{M}-\mathbf{H}^{-}\right.$ & Fragment ions(intensity) & Identification \\
\hline $1^{*}$ & 10.2 & 353.0 & $\mathrm{MS}^{2}: 190.9(100), 353.0(11)$ & 1-CQA \\
\hline 2 & 11.0 & 353.0 & $\mathrm{MS}^{2}: 191.0(78), 179.0(63), 352.9(100)$ & 3-CQA \\
\hline 3 & 12.8 & 353.0 & $\mathrm{MS}^{2}: 191.0(100), 352.9(7)$ & 5-CQA \\
\hline 4 & 13.4 & 353.0 & $\mathrm{MS}^{2}:$ 172.9(100), 179.0(76), 190.8(44), 353.0(88) & 4-CQA \\
\hline 5 & 14.2 & 366.9 & $\mathrm{MS}^{2}:$ 193.0(100), 366.9(47) & 3-FQA \\
\hline $6^{*}$ & 14.5 & 353.0 & $\mathrm{MS}^{2}: 191.0(100), 352.9(10)$ & cis-5-CQA \\
\hline $7 *$ & 14.8 & 515.0 & $\mathrm{MS}^{2}:$ 191.1(100), 179.0(89), 352.9(84) & 1,3-diCQA \\
\hline 8 & 15.2 & 179.0 & $\mathrm{MS}^{1}: 179.0(100)$ & $\mathrm{CA}$ \\
\hline $9 *$ & 15.7 & 337.0 & $\mathrm{MS}^{1}: 336.9(100), 162.7(66)$ & 3-pCoQA \\
\hline 10 & 16.7 & 366.9 & $\mathrm{MS}^{2}: 191.0(100), 366.9(34)$ & 5-FQA \\
\hline 11 & 17.3 & 367.0 & $\mathrm{MS}^{2}: 173.0(100), 192.8(10), 367.0(33)$ & 4-FQA \\
\hline $12 *$ & 17.9 & 367.0 & $\mathrm{MS}^{2}: 191.0(100), 367.0(25)$ & cis-5-FQA \\
\hline $13 *$ & 18.1 & 529.0 & $\mathrm{MS}^{2}: 366.5(15), 193.0(100), 173.0(5)$ & 1C-3FQA \\
\hline $14^{*}$ & 19.6 & 381.0 & $\mathrm{MS}^{1}: 380.9(100)$ & DQA \\
\hline 15 & 20.8 & 515.0 & $\mathrm{MS}^{2}: 191.0(100), 352.7(5)$ & 1,5-diCQA \\
\hline $16^{*}$ & 21.2 & 515.0 & $\mathrm{MS}^{2}: 190.8(100), 353.0(11)$ & cis-1,5-diCQA \\
\hline 17 & 21.7 & 515.0 & $\mathrm{MS}^{2}:$ 191.0(100), 178.9(81), 172.9(62), 334.7(18) 353(95) & 3,5-diCQA \\
\hline 18 & 22.1 & 515.0 & $\mathrm{MS}^{2}:$ 178.9(100), 172.9(73), 190.9(87), 255.0(51), 352.8(83) & 3,4-diCQA \\
\hline $19 *$ & 22.3 & 515.0 & $\mathrm{MS}^{2}: 190.9(100), 179.0(43), 172.9(27), 352.5(37)$ & cis-3,5-diCQA \\
\hline 20 & 22.9 & 515.0 & $\mathrm{MS}^{2}:$ 172.9(100), 179.0(66), 190.9(25), 352.9(93) & 4,5-diCQA \\
\hline $21 *$ & 23.5 & 515.0 & $\mathrm{MS}^{2}:$ 173.1(100), 178.9(88), 190.7(42), 352.9(98) & cis-4,5-diCQA \\
\hline 22 & 24.2 & 529.0 & $\mathrm{MS}^{2}: 190.7(100), 172.8(43), 192.6(29)$ & 1F-5CQA \\
\hline 23 & 24.6 & 529.0 & $\mathrm{MS}^{2}: 191.0(100), 173.0(7), 366.9(21)$ & 1C-5FQA \\
\hline $24 *$ & 25.5 & 515.0 & $\mathrm{MS}^{2}:$ 172.8(100), 178.9(59), 191.0(51), 352.6(87) & cis-4,5-diCQA \\
\hline 25 & 25.9 & 529.0 & $\mathrm{MS}^{2}:$ 173.0(100), 192.7(24), 190.8(23), 367(32), 334.7(9) & 3C-4FQA \\
\hline $26^{*}$ & 26.5 & 542.9 & $\mathrm{MS}^{2}:$ 542.9(100), 380.9(58), 160.7(51) & 3D-5CQA \\
\hline 27 & 26.9 & 529.0 & $\mathrm{MS}^{2}:$ 173.0(100), 178.9(92), 190.9(67), 353.0(85) & 4C-5FQA \\
\hline 28 & 27.4 & 529.0 & $\mathrm{MS}^{2}: 172.9(100), 192.7(45), 366.5(37)$ & 4F-5CQA \\
\hline $29 *$ & 28.2 & 542.9 & $\mathrm{MS}^{2}: 380.8(100), 160.7(57), 179.0(25), 542.8(76)$ & 3D-5CQA \\
\hline $30 *$ & 28.9 & 529.0 & $\mathrm{MS}^{2}:$ 172.9(100), 178.9(29), 191.0(18), 352.8(26), 367(17) & cis-4C-5FQA \\
\hline 31 & 29.1 & 677.0 & $\mathrm{MS}^{2}:$ 515.0(100), 353.0(40), 179.0(10) & 3,4,5-triCQA \\
\hline $32 *$ & 29.3 & 543.0 & $\mathrm{MS}^{2}: 381.0(100), 178.8(52), 160.7(13)$ & 4D-5CQA \\
\hline 33 & 29.7 & 543.0 & $\mathrm{MS}^{2}:$ 193.0(100), 172.9(25), 367.0(37), 348.9(16) & 3,5-diFQA \\
\hline 34 & 30.1 & 543.0 & $\mathrm{MS}^{2}: 349.0(100), 172.6(72)$ & 3,4-diFQA \\
\hline 35 & 31.1 & 543.0 & $\mathrm{MS}^{2}: 172.9(100), 192.6(53), 366.9(40), 349.1(29)$ & 4,5-diFQA \\
\hline 36 & 36.9 & 173.0 & $\mathrm{MS}^{1}: 173.0(100), 126.6(12)$ & Quinic acid \\
\hline
\end{tabular}

*-denotes those identified for the first time in A. апnиa. 


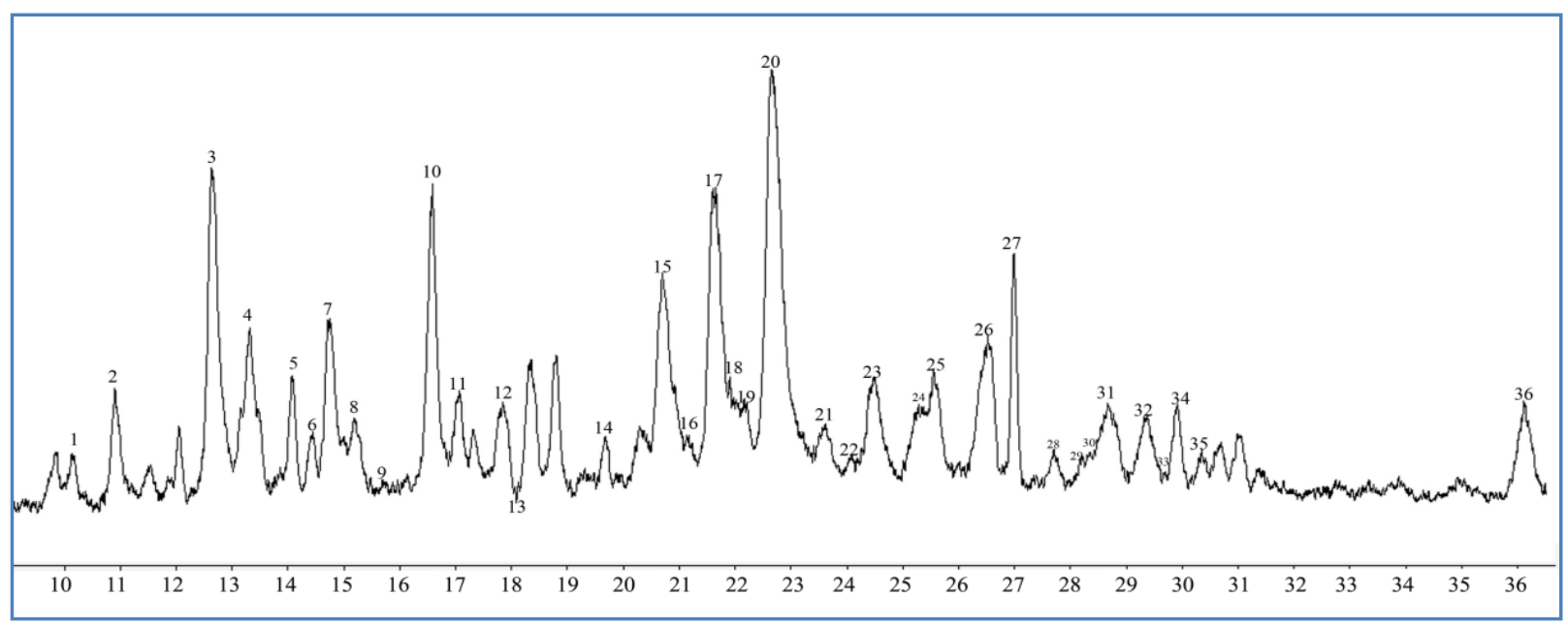

Figure 1 TIC chromatograms of chlorogenic acids extracted by ethyl alcohol in A annua extracts

3.1 Characterization of Caffeoylquinic ( $\mathrm{Mr}$ 354), Dicaffeoylquinic (Mr 516) and Tricaffeoylquinic acid (Mr 678)

Compound 1, 2, 3, 4, 6 displayed a $\left(\mathrm{MH}^{+}\right)^{-}$ion at $\mathrm{m} / \mathrm{z} 353.0$ and four of them were assigned using the hierarchical keys previously developed as the well-known 1-CQA (1), 3-CQA (2), 4-CQA (3) and 5-CQA (4) ((Jaiswal et al., 2010; Jaiswal et al., 2011)). One more peak (6) presented as a minor component and displayed the $\mathrm{m} / \mathrm{z} 191.0$ as the base peak in the $\mathrm{MS}^{2}$ spectrum, identical fragmentation patterns to 5-CQA, and it was suspected that it might be the cis-isomer of the corresponding 5-CQA: cis-5-CQA (Clifford et al., 2005). Compound 7, 15-21, 24 displayed a $\left(\mathrm{MH}^{+}\right)^{-}$ion at $\mathrm{m} / \mathrm{z} 515.0$ and showed similar fragmentation patterns as $\left(\mathrm{M}-\mathrm{H}^{+}-162\right)^{-}$ions at $\mathrm{m} / \mathrm{z}$ 353.0. The diCQA isomers were identified according to the base peaks and the relative intensities of secondary ions formed from $\mathrm{MS}^{2}$ fragmentation of their parent ions at $\mathrm{m} / \mathrm{z}$ 353.0 (Jaiswal et al., 2010; Jaiswal et al., 2011).

Compound 7 showed (m/z 191 (100); m/z 179 (89); m/z 352.9 (84)) in the $\mathrm{MS}^{2}$ spectrum, so it was identified as 1,3-diCQA. Similarly, four diCQAs were assigned as 1,5-diCQA (15), 3,5diCQA (17), 3,4-diCQA (18) and 4,5-diCQA(20) according to their characteristic fragmentation pattern as discussed previously (Clifford et al., 2006). Four other isomers were assigned as cis-1,5-diCQA (16), cis-3,5-diCQA (19), two cis4,5-diCQA (21 and 24) based on their fragmentation pattern. However, it's impossible to distinguish the difference between 4-cis-5-trans-diCQA and 4-trans-5-cis-diCQA or cis-4,5diCQA under these circumstance. The unequivocally identification of these compounds could only be established by NRM studies (Clifford et al., 2006).

Compound 31 displayed a $\left(\mathrm{MH}^{+}\right)^{-}$ion at $\mathrm{m} / \mathrm{z} 677.0$ and $\left(\mathrm{M}-\mathrm{H}^{+}-\right.$ 162) $)^{-} \mathrm{m} / \mathrm{z}$ 515.0. In the $\mathrm{MS}^{2}$ spectrum, it displayed $\mathrm{m} / \mathrm{z} 353.0$ $\left(\mathrm{M}-\mathrm{H}^{+}-324\right)^{-}, \mathrm{m} / \mathrm{z} 179.0$ (caffeoyl acid- $\left.\mathrm{H}^{+}\right)^{-}$. Based on the information available in literature, this isolated compound was identified as 3,4,5-triCQA (Jaiswal et al., 2011).

3.2 Characterization of feruoylquinic acids ( $\mathrm{Mr}$ 368), diferuoylquinic acids (Mr 544)

Compound 5, 10, 11, 12 displayed a $\left(\mathrm{MH}^{+}\right)^{-}$ion at $\mathrm{m} / \mathrm{z} 367.0$ and three of them were assigned 3-FQA (5), 5-FQA (10) and 4-FQA (11) name by using the hierarchical keys previously developed (Jaiswal et al., 2010).

Compound 12 displayed the m/z 191.0 as the base peak in the $\mathrm{MS}^{2}$ spectrum, identical fragmentation patterns to 5-FQA, and it might be the cis-isomer of the corresponding 5-FQA: cis-5FQA. The three isomers diferuloylquinic acid were identified as 3,5-diFQA (33), 3,4-diFQA (34) and 4,5-diFQA (35) based on the previous literature (Jaiswal et al., 2010; Jaiswal et al., 2011).

3.3 Characterization of dimethoxy-cinnamoylquinic acid (Mr 382). caffeoyl- dimeth-oxycinnamoylquinic acids (Mr 544)

Compound 14 displayed a $\left(\mathrm{MH}^{+}\right)^{-}$ion at $\mathrm{m} / \mathrm{z} 381.0$ in negative ion mode ESI-MS , suggesting one dimethoxy cinnamoylquinic acid according to previous studies conducted by Jaiswal et al. (2010). Compound 26, 29, 32 yielded molecular ion at m/z 543.0 and they produced an $\mathrm{MS}^{2}$ base peak at $\mathrm{m} / \mathrm{z}$ 381.0, suggesting caffeoyl dimethoxycinnamoylquinc acids of 3D-4CQA (26), 3D-5CQA (29) and 4D-5CQA (32) (Jaiswal et al., 2010).

3.4 Characterization of caffeoyl-feruloylquinic acids ( $\mathrm{Mr} 530$ ) Compound 13, 22, 23, 25, 27, 28, 30 displayed a $\left(\mathrm{MH}^{+}\right)^{-}$ion at $\mathrm{m} / \mathrm{z}$ 529.0. All of these seven compounds showed $\mathrm{MS}^{2}$ base peaks at either m/z $\left.353.0\left(\mathrm{CQA}^{-\mathrm{H}^{+}}\right)^{-}\right)$or $\mathrm{m} / \mathrm{z} 367.0((\mathrm{FQA}-$ $\left.\mathrm{H}^{+}\right)^{-}$. 
According to Jaiswal et al. (2010), the peak 13 yielded an $\mathrm{MS}^{2}$ base peak at $\mathrm{m} / \mathrm{z} 366.5$, From $\mathrm{MS}^{2}$, the base peak at $\mathrm{m} / \mathrm{z} 193.0$ indicated the presence of feruloyl residue at the 3-position (Clifford et al., 2006). The lower intensity of the $\mathrm{MS}^{2}$ secondary peak at $\mathrm{m} / \mathrm{z} 173.0$ suggesting that isolated compound was 1C-3FQA. According to hierarchical key, they were identified as 1F-5CQA (22), 1C-5FQA (23), 3C-4FQA (25), 4C-5FQA (27), 4F-5CQA (28), Cis-4C-5FQA (30).

Compound 9 displayed a $\left(\mathrm{MH}^{+}\right)$ion at $\mathrm{m} / \mathrm{z} 337.0$ and produced ions at $\mathrm{m} / \mathrm{z}$ 162.7. According to Jaiswal et al. (2010) this isolated compound was identified as 3-coumaroylquinic acid.

The simple phenolic acids were also detected in the extraction. Compound 8 displayed a $\left(\mathrm{M}-\mathrm{H}^{+}\right)^{-}$ion at $\mathrm{m} / \mathrm{z}$ 179.0. In comparison to chemical marker, it was identified as caffeic acid. Compound 36 displayed a $\left(\mathrm{MH}^{+}-\mathrm{H}_{2} \mathrm{O}\right)^{-} 173.0$ and produced ion at $\mathrm{m} / \mathrm{z} 126.6$. According to the observation made by Jaiswal et al. (2010) it was identified as Quinic acid.

A total of 18 chlorogenic acids compounds were identified or tentatively characterized in the methanol extract of A. Аппиа (Gouveia \& Castilho, 2013). Teresa Carbonara characterized and quantified 16 chlorogenic acids compounds in A.аnnua tea
(IUPC, 1976). Furthermore, 40 hydrocinnamic acid derivatives and glycosylated flavonoids were isolated by the acetone extracts (Robinson et al., 1996). As chlorogenic acid has different solubility in different solvents, the numbers of peaks in methanol and acetone extracts were relatively less. Acetone found effective more for artemisinin, but it is ineffective for chlorogenic acids of A. аnnua. Optimized separation methods for extracting chlorogenic acids have been applied in this study. Ethanol : water $(70: 30, \mathrm{v} / \mathrm{v})$ was chosen as the best solvent to improve the separation degree and solubility. This study found that the content of monocaffeoylquinic acids and dicaffeoylquinic acids in $A$. аппиа $L$. were much higher than other compounds. Therefore, the components which separated from the residue can be used for medicine, food and other purposes.

3.5 Purification by Polyamide and Sephadex LH-20

65.86 mg dicaffeoylquinic acid was obtained after concentration with $15 \mathrm{~g}$ A. аnnua. residue and the extraction ratio is $43.90 \%$. After first purification by polyamide, $44.02 \mathrm{mg}$ dicaffeoylquinic acid was obtained with a recovery rate of $66.84 \%$. The purity was $45.7 \%$ after collecting dicaffeoylquinic acid liquid and then freeze drying it.

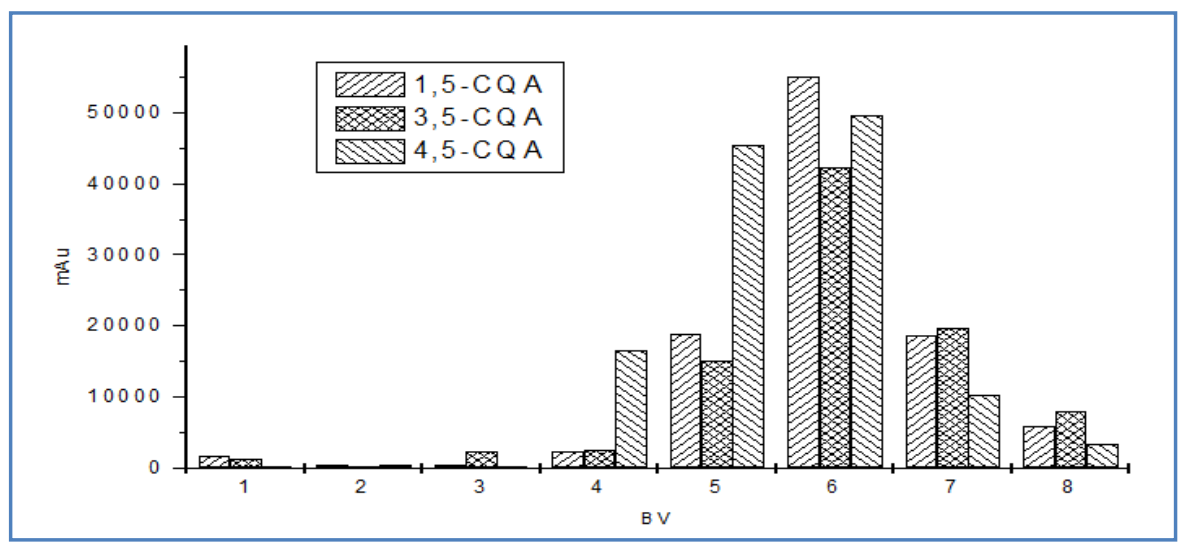

Figure 2 The desorption curve of polyamide

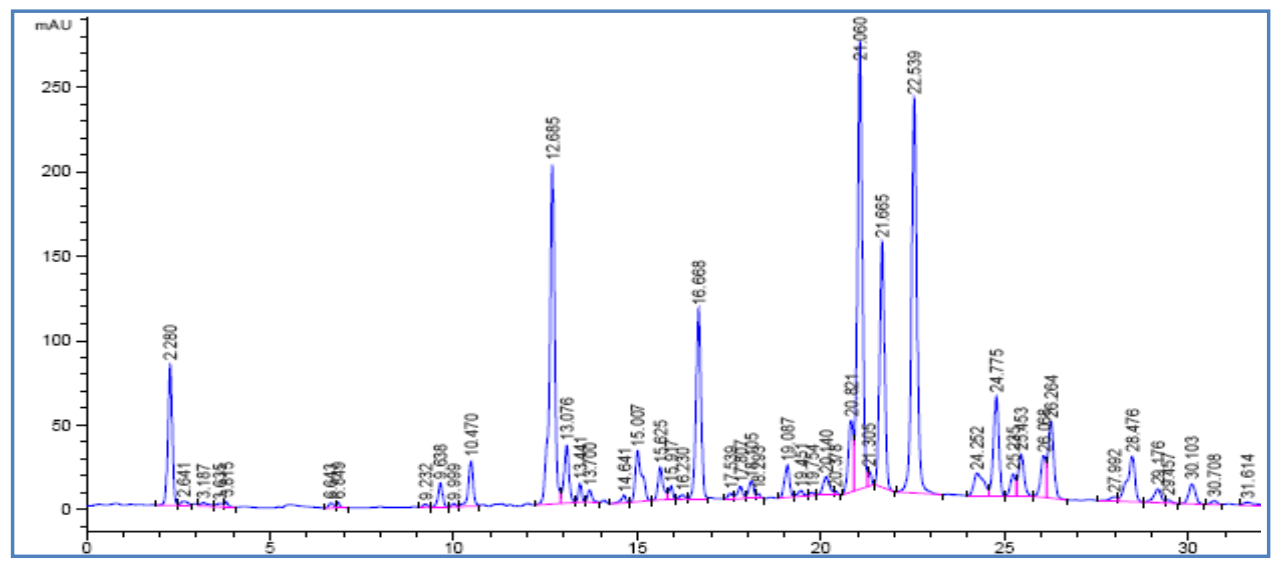

Figure 3 HPLC of chlorogenic acids extracted by ethyl alcohol in A. апnиа residue extracts 


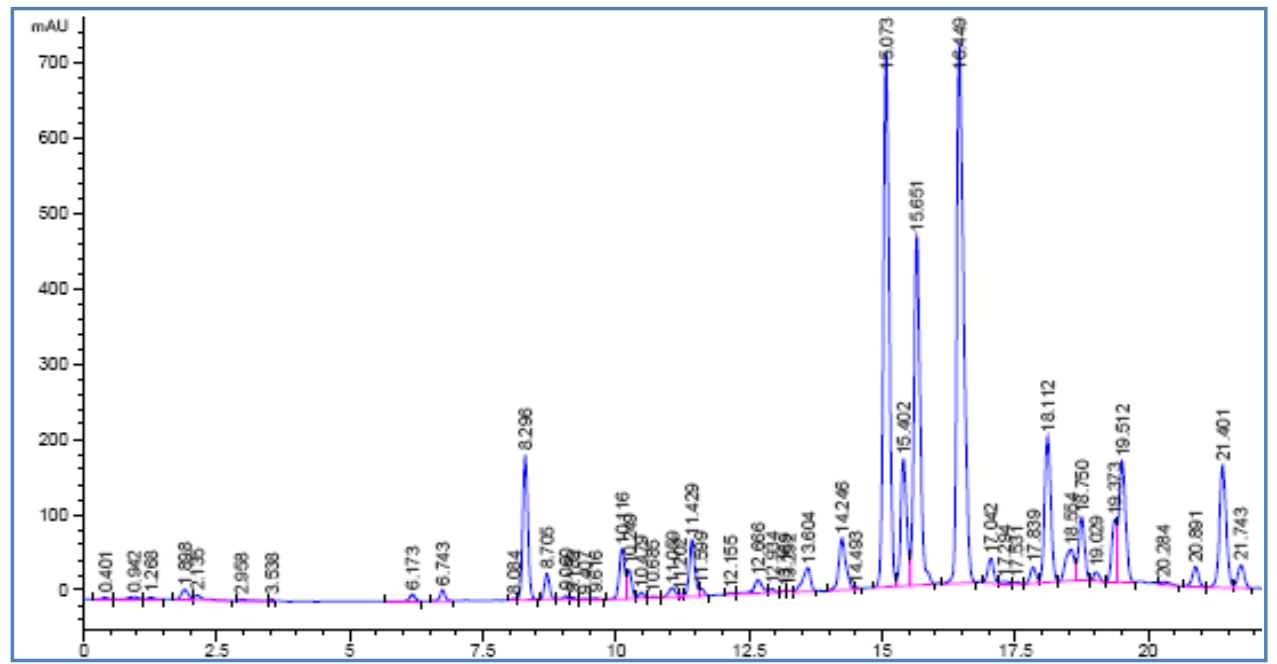

Figure 4 HPLC of polyamide desorption of CQA from A. annua residue extracts

Figure 3 shows that chlorogenic acids are rich in A. апnиа residue extracts, of which the single coffeoylquinic acid was mainly 5-coffeoylquinic acid, dicaffeoylquinic acid liquid was mainly 1,5- dicaffeoylquinic acid, 3,5-dicaffeoylquinic acid and 4,5-dicaffeoylquinic acid.

The adsorption rate of polyamide to dicaffeoylquinic acid liquid is $89.4 \%$ with its desorption rate $99.5 \%$. The desorption rate of polyamide to dicaffeoylquinic acid liquid is higher than the single coffeoylquinic acid $(80.9 \%$. So polyamide can be choosen as the most appropriate material to separate dicaffeoylquinic acid and single coffeoylquinic acid.
Figure 5 shows that SephadexLH-20 can purify dicaffeoylquinic acid effectively and the purity reached $85.7 \%$ with a yield of $53.4 \%$ after the secondary purification by Sephadex LH-20. On the basis of identification chlorogenic acids, dicaffeoylquinic acids isolated from A. аппиа residue, can produce artemisininand which is new sources of raw materials for the production of dicaffeoylquinic acids. It was a new way to get two types of high value-added products from the same raw material, especially for the production of high purity dicaffeoylquinic acids. It has great practical significances for making full use of A. апnиa and provides broad prospects for development for A. аппиа $L$. industry.

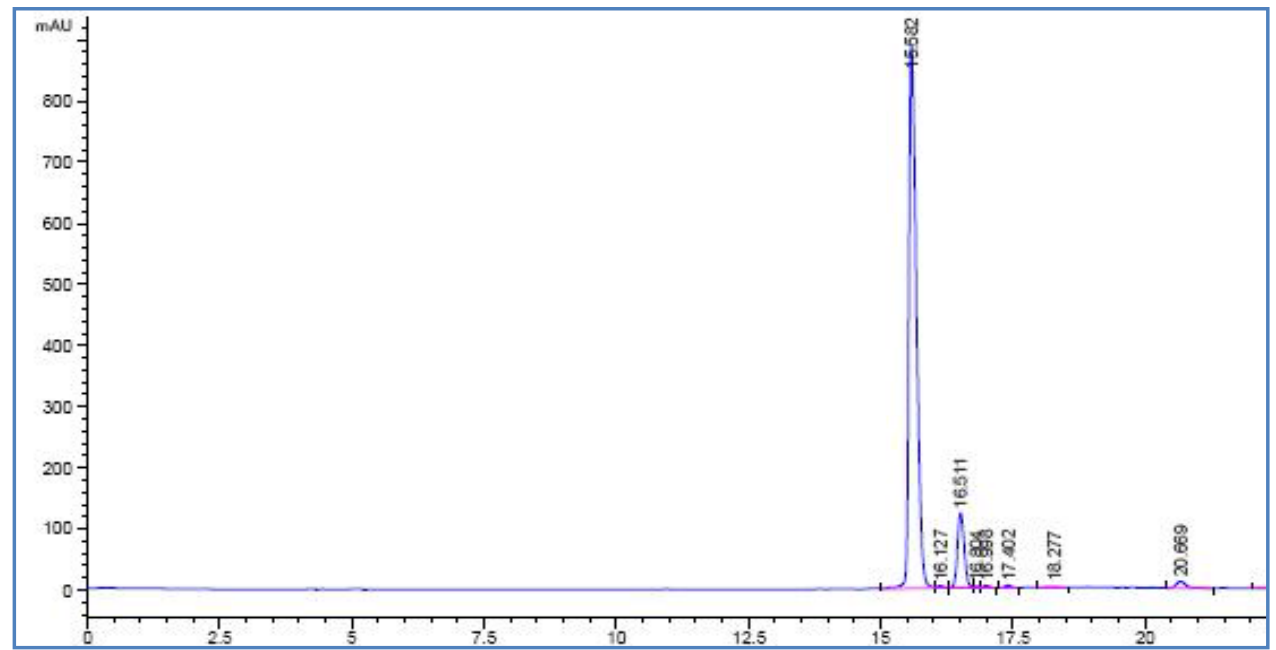

Figure 5 HPLC of CQA from extracts of A. annua residue purified by Sephadex LH-20 
In this study, a reliable and powerful method was established for the comprehensive and accurate identification of chlorogenic acids in A. апnиа. The LC/MS ${ }^{\mathrm{n}}$ system used in this work proved an excellent tool for identifying structures of different components, particularly for isomers. Thirty-six chlorogenic acids were successfully identified by MS spectra compared with standards or literature data. Fifteen were reported first time from A. аппиа. The purification method for dicaffeoylquinic acid provides effective use of chlorogenic acids, which were previously wasted in А.апnиa residue. Therefore, this work will promote the sustainable use of A.аnnua resources with great economic, social and environmental benefits.

\section{Acknowledgments}

This work was supported in part by a research grant from Key Projects of Natural Science Research in Universities in Jiangsu Province and Project for Advantage Life Science of Jiangshu Province and Open Project of Jiangsu Key Laboratory for Biodiversity and Biotechnology.

\section{Conflict of Interest}

We declare that we do not have any commercial or associative interest that represents a conflict of interest in connection with the work submitted.

\section{References}

Carbonara T, Pascale R, Argentieri MP, Papadia P, Fanizzi FP, Villanova L, Avato P (2012) Phytochemical analysis of a herbal tea from Artemisia annua L. Journal of Pharmaceutical and Biomedical 62:79-86. doi:10.1016/j.jpba.2012.01.015.

Clifford MN, Johnston KL, Knight S, Kuhnert N (2003) Hierarchical Scheme for LC-MS ${ }^{\mathrm{n}}$ Identification of Chlorogenic Acids. Journal of Agricultural and Food Chemistry 51: 29002911. doi: 10.1021/jf026187q.

Clifford MN, Knight S, Kuhnert N (2005) Discriminating between the Six Isomers of Dicaffeoylquinic Acid by LC-MS ${ }^{\mathrm{n}}$. Journal of Agricultural and Food Chemistry 53: 3821-3832. doi: 10.1021/jf050046h.

Clifford MN, Knight S, Surucu B, Kuhnert N (2006) Characterization by LC-MS $^{\mathrm{n}}$ of Four New Classes of Chlorogenic Acids in Green Coffee Beans: Dimethoxycinnamoylquinic Acids, Diferuloylquinic Acids, Caffeoyl-dimethoxycinnamoylquinic Acids, and Feruloyldimethoxycinnamoylquinic Acids. Journal of Agricultural and Food Chemistry 54: 1957-1969. doi: 10.1021/jf0601665.

Clifford MN, Marks S, Knight S, Kuhnert N (2006) Characterization by LC-MS ${ }^{(\mathrm{n})}$ of four new classes of $\mathrm{p}$ - coumaric acid-containing diacyl chlorogenic acids in green coffee beans. Journal of Agricultural and Food Chemistry 54: 4095-4101. doi: 10.1021/jf060536p.

Clifford MN (2000) Chlorogenic acids and other cinnamates nature, occurrence, dietary burden, absorption and metabolism. Journal of the Science of Food and Agriculture 80: 1033-1043. doi: 10.1002/(SICI) 1097-0010(20000515)80:7<1033::AIDJSFA595>3.0.CO;2-T.

Ferreira JF, Luthria DL, Sasaki T, Heyerick A (2010) Flavonoids from Artemisia annua $L$. as antioxidants and their potential synergism with artemisinin against malaria and cancer. Molecules 15: 3135-3170. doi: 10.3390/molecules 15053135

Gouveia SC, Castilho PC (2013) Artemisia annua L.: Essential oil and acetone extract composition and antioxidant capacity. Industrial Crops and Products 45: 170-181. doi:10.1016/j.indcrop.2012.12.022.

Gu R, Dou G, Wang J, Dong J, Meng Z (2007) Simultaneous determination of 1,5-dicaffeoylquinic acid and its active metabolites in human plasma by liquid chromatographytandem mass spectrometry for pharmacokinetic studies. Journal of Chromatography B 852: 85-91. doi:10.1016/j.jchromb.2006.12.055.

Han J, Ye M, Qiao X, Xu M, Wang BR, Guo DA (2008) Characterization of phenolic compounds in the Chinese herbal drug Artemisia апnиa by liquid chromatography coupled to electrospray ionization mass spectrometry. Journal of Pharmaceutical and Biomedical Analysis 47: 516-525. doi:10.1016/j.jpba.2008.02.013.

IUPAC (1976) Nomenclature of cyclitols. Biochemistry 153: 23-31.

Jaiswal R, Deshpande S, Kuhnert N (2011) Profiling the chlorogenic acids of Rudbeckia hirta, Helianthus tuberosus, Carlina acaulis and Symphyotrichum novae-angliae leaves by LC-MSn. Phytochemical Analysis 22: 432-441. doi: 10.1002/pca.1299.

Jaiswal R, Sovdat T, Vivan F, Kuhnert N (2010) Profiling and characterization by LC-MSn of the chlorogenic acids and hydroxycinnamoylshikimate esters in maté (Ilex paraguariensis). Journal of Agricultural and Food Chemistry 58: 5471-5484. doi: 10.1021/jf904537z.

Lai JP, Lim YH, Su J, Shen HM, Ong CN (2007) Identification and characterization of major flavonoids and caffeoylquinic acids in three Compositae plants by LC/DAD-APCI/MS. Journal of Chromatography B 848: 215-225. doi:10.1016/j.jchromb.2006.10.028.

Lubbe A, Seibert I, Klimkait T, van der Kooy F (2012) Ethnopharmacology in overdrive: the remarkable anti-HIV 


\section{2 activity of Artemisia annua. Journal of Ethnopharmacology 141:854-859. doi:10.1016/j.jep.2012.03.024}

Mueller MS, Karhagomba IB, Hirt HM, Wemakor E (2000) The potential of Artemisia annua $L$. as a locally produced remedy for malaria in the tropics: agricultural, chemical and clinical aspects. Journal of Ethnopharmacology73:487-493. doi:10.1016/S0378-8741(00)00289-0.
Robinson WE, Reinecke MG, Abdel-Malek S, Jia Q, Chow SA (1996) Inhibitors of HIV-1 replication that inhibit HIV integrase. Proceedings of the National Academy of Sciences of the United States of America 93:6326-6331.

Willcox ML, Burton S, Oyweka R, Namyalo R, Challand S, Lindsey K (2011) Evaluation and pharmacovigilance of projects promoting cultivation and local use of Artemisia annua for malaria. Malaria Journal 10: 84. doi:10.1186/14752875-10-84. 